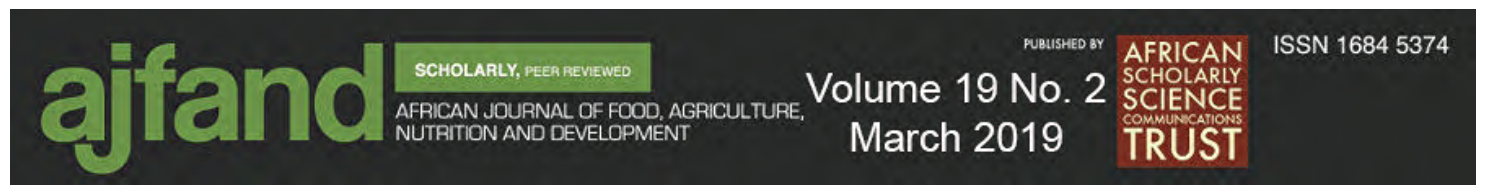

Afr. J. Food Agric. Nutr. Dev. 2019; 19(2): 14337-14353

DOI: 10.18697/ajfand.85.16845

\title{
SANITATION FACILITIES AND PRACTICES FOR STREET-VENDED MEATS AT TWO MAJOR HIGHWAY MARKETS IN UGANDA
}

\section{Bagumire $\mathbf{A}^{1}$ and R Karumuna ${ }^{2 *}$}

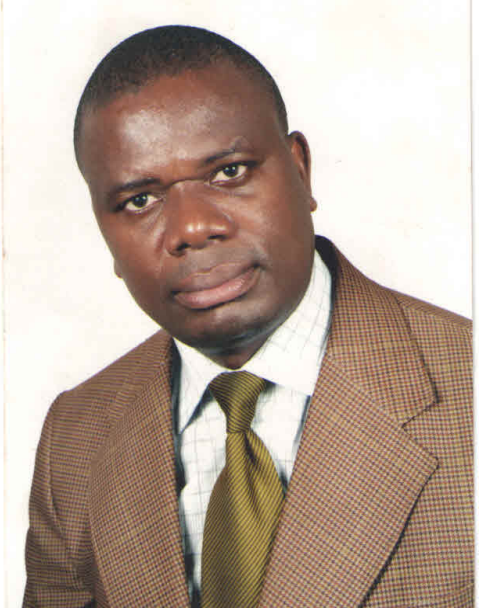

Ananias Bagumire

*Corresponding author email: karumunaroland@gmail.com

${ }^{1}$ Ananias Bagumire. National Food Safety Foundation (NFSF), the affiliated institution of the Food Safety Associates Limited, Plot 1099, Block 215, Kondogolo Zone, Ntinda-Kulambiro, off Ntinda-Kisasi Road, P.O.Box 2244 Kampala-Uganda

${ }^{2}$ Rollanda Karumuna. Department of Environment Management, College of Agriculture and Environmental Sciences, Makerere University, P.O Box 7062 Kampala, Uganda 


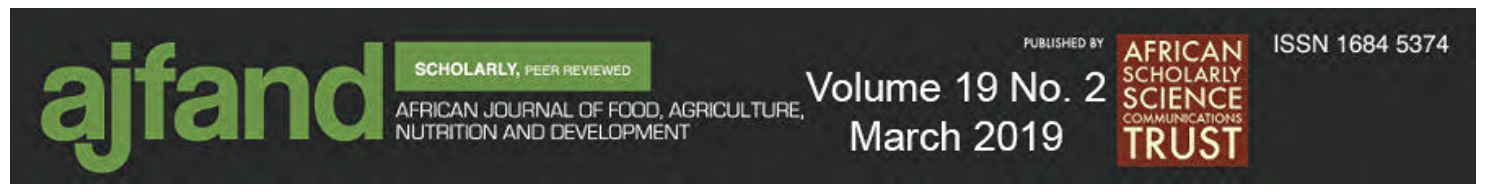

\section{ABSTRACT}

A study on sanitation facilities and practices for vendors of ready-to-eat roasted meat at selected highway markets was conducted. The aim of the study was to establish the status of sanitation in the markets and its effect on the safety of ready-to-eat roasted meat. Recommended conditions for sanitation facilities were assessed in stalls of chicken, beef and goat meat vendors using checklists. Questionnaires were also administered among 180 meat vendors to assess their sanitation practices. A scale of 0 4 was used to assess the conformity of sanitation facilities where $4=$ High level conformity, $3=$ Good conformity, $2=$ Fair conformity, $1=$ Low conformity and $0=$ Nonconformity. Majority $(67 \%)$ of the sanitation facilities evaluated had average score below 2. Waste management facilities were most deficient to the recommended conditions with a score of 0.85 . Better performance was found in most roofs of vending structures (2.93). Over $78 \%$ of the stalls assessed did not have waste collection facilities and, therefore, scored 0 denoting non-conformity, $68 \%$ of the stalls did not have adequate water and therefore scored 0 denoting non-conformity to conditions of water availability. For shared facilities, toilet/latrine in both markets had an average score of 1.5 denoting a low level of conformity. Both markets scored 0 for waste water disposal facilities denoting non-conformity to the two recommended conditions for waste water disposal facilities, and were therefore non-compliant. The low conformity obtained from the assessment of facilities concurred with results from the assessment of sanitation practices; $67 \%$ lacked sufficient knowledge about good sanitation practices, $91 \%$ did not sort their wastes, $83 \%$ did not have adequate waste handling facilities and therefore they poorly collected their wastes, $76 \%$ of the vendors indicated inadequate latrine facilities as one of their sanitation challenges, $73 \%$ had inadequate cleaning materials and $70 \%$ did not clean their food stuffs. However, majority of vendors $(92 \%)$ indicated that they clean their premises. Therefore, sanitation facilities and practices in highway markets did not conform to best recommended conditions. This could expose meats to contamination and compromise consumer's health. Highway food vendors should be trained in proper sanitation practices. Local authorities need to monitor and enforce good sanitation practices.

Key words: Conformity, Highway markets, Ready-to-eat foods, Sanitation, Meat, Uganda, Practices, Vendors 


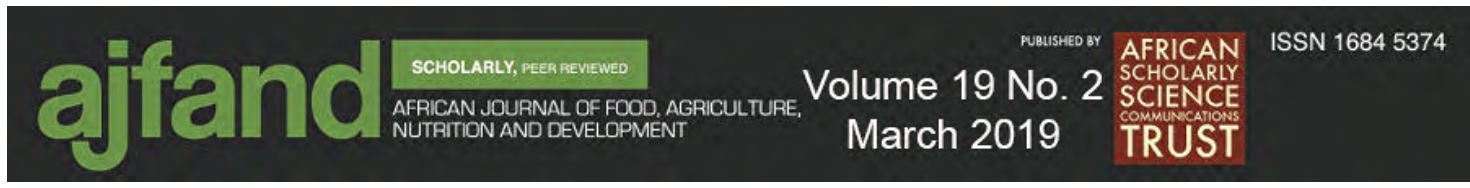

\section{INTRODUCTION}

Availability of proper and adequate sanitation facilities and observing appropriate sanitation practices is important to ensure the safety of vended foods in markets; including highway markets. Sanitation involves prevention of human contact with the hazards of wastes as well as the treatment and proper disposal of sewage waste water. Sanitation also covers provision and use of clean water [1].

In most countries, highway food vending industry plays an important role in meeting the food demands of the travelersand residents around. Highway foods feed thousands of people daily with a wide variety of foods that are relatively cheap and easily accessible [2]. The business of highway food vending emerged out of the need by the travelers to access ready-to-eat food as they travel. This form of food trade involves vendors who prepare food at strategic roadside points where vehicles with travelers stop [3]. The vending involves selling of ready-to-eat foods on roasting sticks or in containers to travelers in vehicles that stop by the road side at the highway market points. The trade is mostly run by young men and women [4].

In Uganda, the practice is not any different; food vending is done by young and less educated men and women who start early in the morning and work until late in the night selling food to customers in the passing vehicles who mainly buy through the windows of the vehicles. The foods sold include roasted cassava, potatoes, chicken, beef, goat meat and plantain "gonja" among other foods. They are prepared using charcoal stoves locally called "Sigili" in stalls built with wooden poles and roofs made of either iron sheets or papyrus reeds [5].

The sanitation of highway markets in Uganda is not well monitored. Neither are the markets adequately regulated, which could expose travelling consumers to the risk of consuming unsafe food. The unlimited and unregulated growth of highway food vending markets may contribute to outbreak of gastrointestinal food borne illnesses such as cholera, diarrhea, stomach cramps, Listeroisis, hepatitis, anthrax, Brucella among other illnesses that arise from consumption of contaminated foods as a result of poor sanitation [6]. There was an estimated 1.4 million hospitalizations in 2012 in Uganda attributed to food borne related afflictions, although it may not be clear as to how many of such cases arose from consumption of contaminated highway vended foods [7].

There has been severe strain on sanitation facilities in food markets. The most lacking and inadequate are latrines, waste disposal sites, waste water drainage facilities, water sources and food preparation areas due to the increasing volume of waste arising from congestion and littering in food markets [1]. Like it is the case elsewhere, the highway food vendors in Uganda are often unlicensed, untrained in food sanitation and work under poor sanitary conditions [8]. Most highway food vendors keep inadequate water, do not wash the foods they sell before preparation and do not clean their premises regularly. Even if they wash their food, the water they use for washing the food is dirty. Vendors are supposed to wash their foodstuffs to remove soil, sand, dung and other small particles such as grass that might go on the meat because the conditions of the 


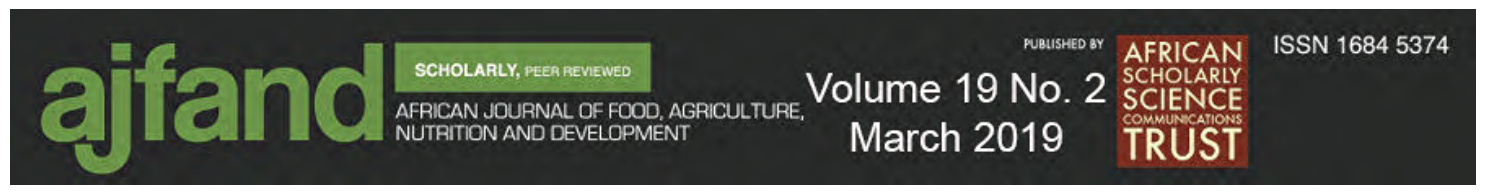

slaughtering sheds are poor and slaughtering is done on the ground. They also have no waste collection facilities and they operate from stalls with dilapidated walls, leaking roofs and earthen $[9,10]$. All these can result in contamination of food that vendors handle.

The poor sanitation in areas where vended food is prepared and the resultant lack of guarantee regarding the safety of ready-to-eat foods that are sold in markets could potentially scare away some customers due to fear of the effects such food may have on their health [6]. The effect is even much higher as regards to the highway markets where even the basic essential sanitation facilities and practices that could be found in other markets are always missing due to the temporary and make-shift nature of facilities and operators in these markets. Rejection of highway vended foods by travellers would lead to reduced sales and income of individuals and households of the food vendors, which has a cascading effect of reduction in tax collection by local authorities, hence having a wider impact on the economy [6]. It is, therefore, vital to understand the extent of sanitation in these markets and how sanitation within the highway markets could affect the safety of ready-to-eat food sold in those markets.

\section{MATERIALS AND METHODS}

\section{Selection of study sites}

Two highway markets (Lukaya and Najembe) were selected for this study. The two are among the major highway markets found on major roads leading out of Kampala city. Najembe market is located approximately $45 \mathrm{~km}$ on Kampala-Jinja highway in Buikwe district heading to the eastern part of Uganda. Lukaya market is located approximately $100 \mathrm{~km}$ on Kampala-Masaka highway in Kalungu district heading to the southern and western parts of Uganda. These markets were also selected for the study because they had a large population of vendors when compared to other highway markets.

\section{Selection of products studied}

The study concentrated on high risk ready-to-eat products that are sold in highway markets. The identification of high-risk products was based on the U.S. Food and Drug Administration (US FDA) guidelines for identifying high risk foods [10]. The types of foods vended in the two markets that are more likely to be implicated as vehicles of food poisoning organisms and lead to gastrointestinal infections (illness) were included for the study. These types of foods are normally high in protein and require strict temperature control and protection from contamination [11]. They included roasted meat and poultry products such as beef, pork, lamb, chicken, turkey and duck. The study concentrated on highway roasted meats of chicken, beef and goat meat. These products are very popular among travelers in Uganda and are mainly sold as roasted ready-to-eat products [12].

\section{Selection of the vendors and stalls for the study}

\section{Selection of stalls used in the assessment of sanitation facilities}

A total of 41 stalls of chicken, beef and goat meat were selected from Lukaya and Najembe markets. The stalls are raised using wooden poles and roofed with either iron sheets or grass; some have short walls that are raised to about 2 metres above the 


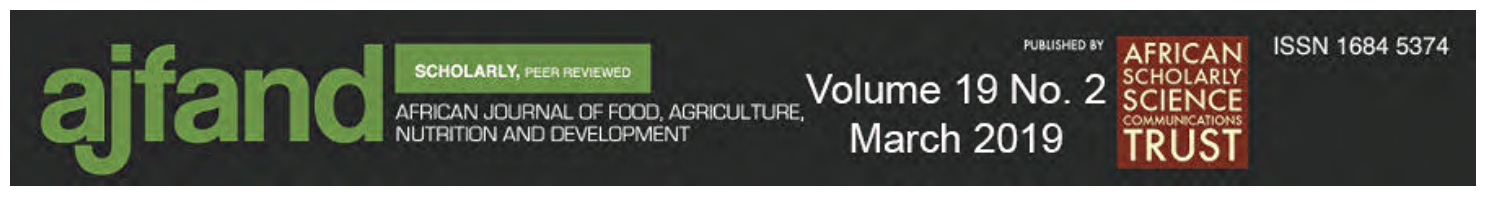

ground (window level) and their floors are either made of soil or rough concrete. In Najembe market, 9 stalls for chicken, 7 stalls for goat meat and 5 stalls for beef were selected (total 21). In Lukaya, 7 stalls for chicken, 5 stalls for goat meat and 8 stalls for beef were selected (total 20). The 41 stalls were arrived at after conducting an assessment of stalls for ownership and the mode of operation. The assessment was conducted by holding meetings with the leadership of the markets in which the chairpersons assisted in identifying the owners of the stalls. This was followed by inquiries among the owners (vendors) about the mode of operation of stalls. Only those who sold one of the meat products were selected $[12,13]$.

\section{Selection of vendors used to assess the status of sanitation practices}

After assessing the ownership and mode of operation in the markets, 30 vendors each for chicken, goat meat and beef were selected randomly from each market to respond to the prepared set of questions in the questionnaire totalling to 90 vendors who responded to the questions in each market. A total of 180 vendors were, therefore, selected from the two markets. Only vendors, whose stalls were assessed for sanitation facilities, were selected for this interview $[12,13]$.

\section{Research Instruments and tools}

\section{Development of the checklists for assessing the sanitation facilities}

Two checklists were formulated; one for assessing the sanitation facilities at stalls of individual vendors and the other one for assessing the shared sanitation facilities such as latrine/toilet facilities, solid waste disposal facilities and waste water disposal facilities. The elements that formed the basis for evaluating the conditions of sanitation facilities in the checklists were adopted from the relevant sections of the FAO/WHO Codex Alimentarius Commission international standards which relate to sanitation facilities of food vending markets. Specifically, the FAO/WHO regional guidelines for the design of control measures for street-vended foods (Africa) of 1997 were used after some amendments to benchmark the sanitation facilities in the highway markets in Uganda [14]. Uganda's Food and Drug Act (1964)-part II (Offences in connection with preparation and sale of injurious foods, general protection for purchasers of food and offence to sell of food unfit for human consumption) [15] and Public Health Act-1969 (part XII-protection of food stuffs, part X-special provisions as to sewerage and drainage and part IX — sanitation and housing) [16] were also respectively reviewed and relevant provisions that are aligned to the modern food sanitation best facilities were incorporated in the checklist. Also incorporated in the checklists were relevant sections in the manual of standard operating procedures for fish inspection and quality assurance $[12,17]$.

The checklist for assessing sanitation facilities at the vendors' stalls was formulated with three (3) detailed sections. The sections covered (1) conformity to recommended conditions of waste management, (2) conformity to recommended conditions of water and (3) conformity to recommended conditions for cleanliness; environment and cleaning equipment. The checklist for assessing the shared sanitation facilities was also developed with three (3) sections covering (1) latrine/toilet facilities, (2) solid waste disposal facilities and (3) waste water management facilities. 


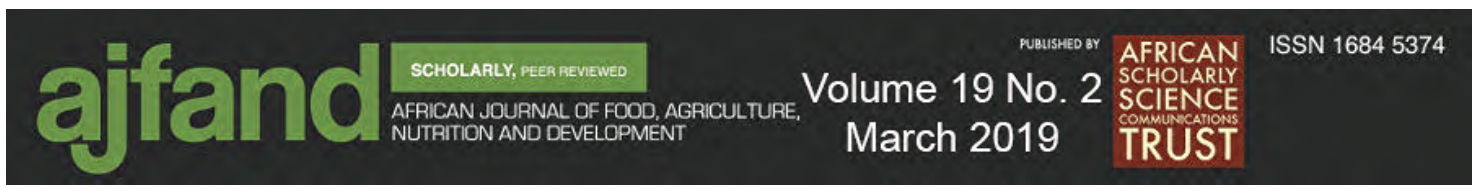

Specific recommended conditions for best sanitation facilities under each of the particular requirements or elements were included in the checklists. In developing the checklist, the format and approach used by relevant authors was adapted with some modifications $[12,17]$.

\section{Questionnaire for assessing the status of sanitation practices}

Nine (9) detailed questions were formulated each comprised of specific sanitation practices to be assessed. The questions covered sanitation challenges faced by vendors, how vendors overcome the challenges, and solutions that vendors could suggest for addressing the sanitation challenges. The questionnaire also covered procedures for cleaning and sanitizing, frequency of cleaning premises, availability of standard cleaning procedures, cleaning of foodstuffs, frequency of change of water that is used for washing food contact items and food; as well as vendors' training in sanitation [12].

\section{Discussion guide}

A discussion guide was developed. This was used during the Focus Group Discussion with the leadership of the market. The discussion guide covered water quality, state of sanitation facilities, cleaning and sanitizing, frequency of cleaning premises, availability of standard cleaning procedures, cleaning of food stuffs, frequency of change of water that is used for washing food contact items and food [12].

\section{Assessment of the sanitation facilities and practices}

An inspection approach for food markets was adapted to carry out a study of sanitation facilities in the selected highway markets. Prior to the study of sanitation facilities in selected highway markets, reconnaissance visits were undertaken to Najembe and Lukaya markets. Contact persons were identified and field data collection schedules arranged with market authorities during the reconnaissance visits. Among the key contacts used were the chairpersons of the market vendors, the local health authorities and security personnel. During the scheduled field visits, meetings were first held with the chairpersons of the market vendors where protocols for collecting the data were explained and understood by the leaders. A guided tour around the market was conducted and sanitation facilities at the stalls and shared facilities were examined for chicken, beef and goat meat vendors through observation. The checklists were used to assess the facilities by ticking the elements of the recommended conditions in the checklist that were observed to be complied with by the stalls or shared facilities. After assessing the facilities, interviews were held with vendors to establish the sanitation practices undertaken by vendors using questionnaires. At the end of the interviews with the vendors, an FGD was conducted with the leaders of the markets to clarify on the responses obtained from the vendors [12].

\section{Data Analysis}

\section{Data from checklists}

The scale of scores from 0 to 4 where zero denoted non-conformity to recommended conditions while 4 denoted high level conformity to recommended conditions was developed. The score scale had intermediary levels of conformity representing low conformity (1), fair conformity (2) and good conformity (3) [12]. 


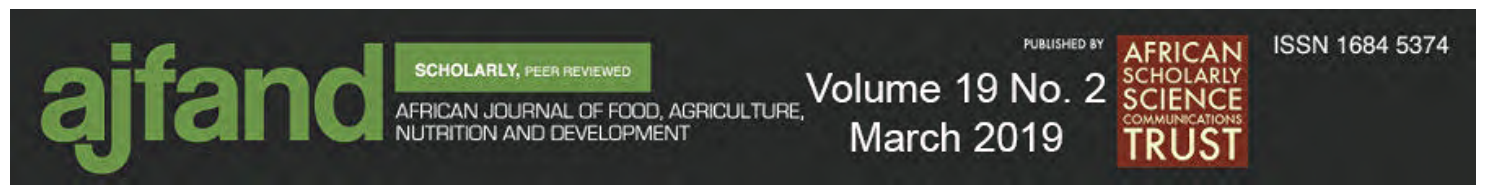

The requirements ticked during assessment of facilities were first denoted by 1 score, while the requirements not ticked were denoted by zero $(0)$ score. All elements used to evaluate conformity with recommended conditions in 41 checklists that were used at the stalls were allocated 1 or zero depending on the observations made. The sanitation requirements/elements in the checklists that were ticked were then counted and the number of requirements/elements ticked was then expressed as a fraction out of the total number of requirements/elements (for each facility) investigated as was included in the checklist. The generated fraction was then multiplied by 4 the score given to conditions for full compliance (conformity). For example, if a facility had 10 requirements/elements to be investigated in the checklist and had scored 6/10 requirements then this fraction would be multiplied by 4 (like for example $6 / 10 \times 4$ ) since 4 was the score that denoted full compliance. The result of the calculation became the final score for a particular facility.

The formula used to calculate final scores is expressed below:

\section{Number of requirements/elements ticked as}

Conforming to required conditions

Total number of recommended conditions for the facility investigated

\section{x 4 (the highest level of conformity)}

Final scores for each requirement and facility were sorted, coded and entered in the computer statistical package for social scientists (SPSS) where high level of conformity was coded 4, good conformity was coded 3, fair conformity was coded 2, low conformity was coded 1 and non-conformity was coded 0 . Then using descriptive statistics percentages (\%) of scores for each of the conditions investigated in the two markets were generated, tabulated and compared as appropriate [12].

\section{Data from questionnaires}

A coding list was generated, which was then used to enter all the responses given in the questionnaires. The coding process involved examining the raw qualitative data in the questionnaires and discussion sheets which was in the form of words, phrases, sentences or paragraphs and assigning them CODES or labels. For example, if a question had options $a, b, c, d$ and e the following codes were given, $a=1, b=2, c=3$, $\mathrm{d}=4$ and $\mathrm{e}=5$. The codes given were entered in SPSS to represent the responses obtained from the vendors of Lukaya and Najembe markets. Descriptive statistics were used to generate frequencies and percentages [12].

\section{RESULTS}

Conformity of waste management facilities at the stalls to recommended conditions Conformity of waste management facilities at the stalls to recommended conditions was low in both markets. Fifty four percent (54\%) of the stalls assessed for existence of wastes scored 1 denoting a low level of conformity, $37 \%$ of the stalls scored 0 denoting 


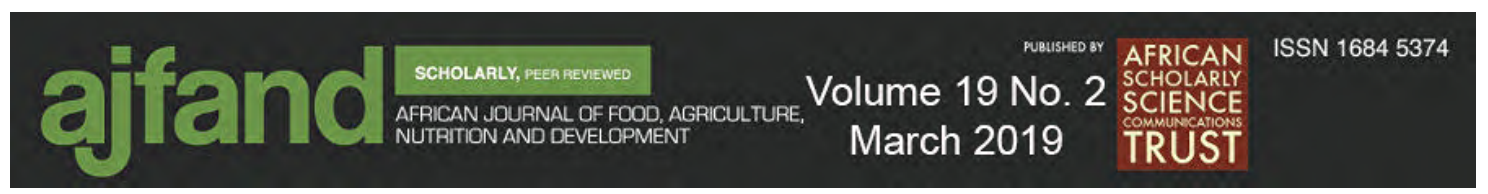

non-conformity. Only $10 \%$ of the stalls assessed scored 3 denoting a good level of conformity to recommended conditions and none of the stalls scored 4 (Table 1).

Sorting of solid wastes was not done in over $93 \%$ of the stalls assessed as shown by the poor scores obtained in both markets, which indicates non-conformity to recommended conditions (Table1). The poor scores obtained under sorting of wastes concurred with the responses from the assessment of the conformity of vendors' practices to recommended conditions done using a questionnaire in which $91 \%$ of the vendors indicated that they did not sort wastes at their stalls (Table 4).

Concerning availability of waste collection facilities, $78 \%$ of the stalls assessed in both markets (Lukaya and Najembe) did not have waste collection facilities (not even sacks or boxes to put wastes) and, therefore, scored 0 denoting non-conformity. As for effectiveness of the waste collection facilities, assessment was done in the remaining $22 \%$ that had waste collection facilities. Of those facilities that had waste collection facilities, $18 \%$ scored 1 denoting a low level of effectiveness of the facilities, $2 \%$ scored 2 denoting fair level of effectiveness and 3\% scored 3 denoting good level of effectiveness (Table 1).

The scores obtained on existence of waste collection facilities were in agreement with the responses from the assessment of vendor's sanitation practices done using a questionnaire in which $83 \%$ of the vendors indicated that they did not have adequate waste handling facilities at their stalls (Table 4).

Although there appeared to be differences in the levels of conformity to recommended conditions of waste management at the stall in the two markets (Najembe and Lukaya) where the situation was observed to be worse in Lukaya as compared to Najembe market Table 1, the difference was not significant (Mann-Whitney U-test for significance - $U>5$ ).

\section{Conformity to recommended conditions of water supply at the stall}

On average, $61 \%$ of the stalls at Lukaya and Najembe market observed for availability of water scored 4 denoting high level conformity while $39 \%$ of the stalls scored 0 denoting none-conformity to recommended conditions indicating that they did not have water. However, $68 \%$ of the stalls that were found to have water did not have it in adequate quantities and, therefore, scored 0 denoting non-conformity to conditions of water adequacy. Only $32 \%$ of the stalls had adequate water and, thus, scored 4 denoting high level conformity to conditions of water adequacy (Table 2).

Water quality was also observed during assessment of sanitation facilities. For those stalls that had water; only $5 \%$ scored 4 denoting a high level of conformity to recommended conditions for quality water, $22 \%$ scored 3 denoting a good conformity to recommended conditions while the rest $(38 \%, 23 \%$ and $12 \%)$ scored 2 (fair level of conformity), 1 (low level of conformity) and 0 (non-conformity) respectively (Table 2). The high percentage of stalls with inadequate water facilities tallied with the results obtained from the assessment of practices in which $71 \%$ of the vendors indicated lack 


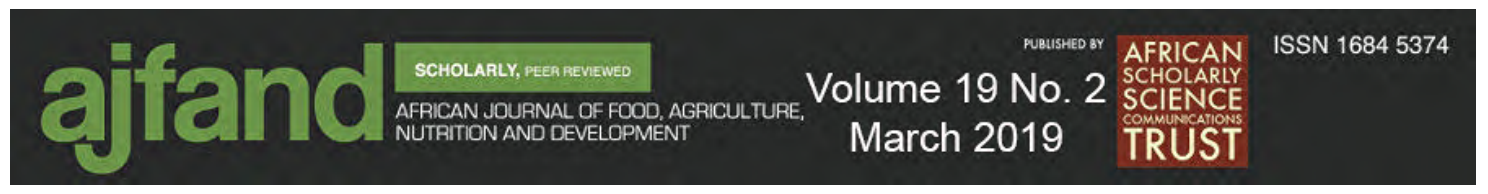

of enough sources of clean water as one of their challenges in ensuring good sanitation practices (Table 4).

Although there were observable differences in the levels of conformity to recommended conditions of water at the stall in the two markets where the situation was observed to be slightly worse for Najembe as compared to Lukaya (Table 2), a Mann-Whitney U-test for significance revealed that the values obtained were not significantly different $(\mathrm{U}>5)$.

\section{Conformity of shared facilities (toilet/latrine, solid waste and waste water management facilities) to recommended conditions}

For shared facilities, toilet/latrine in Najembe market had an overall score of 1 denoting a low level of conformity, while those in Lukaya market had an overall score of 2 denoting a fair level of conformity (Table 3). The shared facilities (toilets and latrines) in Najembe market scored 4 out of eleven (11) recommended conditions (distance from the stalls, condition of the walls and absence of flies and presence of doors). Excreta facilities in Lukaya market scored 6 out of eleven (11) recommended conditions (latrine/toilet adequacy, condition of the walls, condition of the roofs, presence of doors, presence of a hand washing place and label indicating toilet/latrine location). The low level of conformity observed in excreta facilities of Najembe market concurred with the findings from the assessment of sanitation practices in which $76 \%$ of the vendors in Najembe market indicated inadequate latrine facilities as one of their sanitation challenges. Interviews with vendors also indicated that $69 \%$ had inadequate waste disposal facilities (Table 4). Both markets scored 0 for waste water disposal facilities denoting non-conformity to the two recommended conditions for waste water disposal facilities, and were therefore non-compliant (Table 3).

Although there were differences in scores of conformity to recommended conditions for toilet/latrine, solid waste and waste water management facilities in Najembe and Lukaya markets (Table 3); a Mann-Whitney U-test for significance indicated that the differences were not significant $(U>5)$.

\section{Comparison of sanitation facilities for chicken, beef and goat mean}

The overall mean score of sanitation facilities for all the three products (chicken, beef and goat meat) was 1.51. This is a low level of conformity to recommended conditions of sanitation facilities on the scoring scale of 0-4. Sanitation facilities for beef in both markets had the highest mean score (1.66), followed by the sanitation facilities of goat meat (1.49). The lowest mean score (1.39) was recorded in the sanitation facilities of chicken stalls. Much as there is an observable difference in the mean scores obtained from the assessment of sanitation facilities for vended chicken, beef and goat meat in Najembe and Lukaya markets, analysis of variances (ANOVA) between the mean scores of sanitation facilities of the three products indicated that they were not significantly different $(\mathrm{P}>0.05)$. 


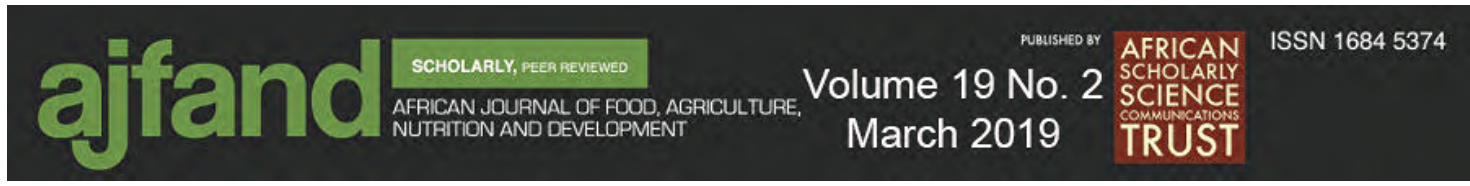

\section{DISCUSSION}

Conformity of waste management facilities at the stalls to recommended conditions Conformity of waste management facilities at the stalls to recommended conditions was low in both markets. The immense existence of wastes at most stalls is explained by inadequate waste collection facilities at stalls. The vendors did not have facilities to temporarily put the different waste materials generated and therefore ended up dropping them on to the ground as they looked forward to sweeping them the next time they were to sweep around their stalls. A similar situation was reported to occur in public eating places in Fort Portal municipality-Uganda [1]. Inadequate waste collection facilities, congestion and lack of regular monitoring of the markets by the local health inspectors were among the reasons why wastes laid uncollected around most kiosks of food vendors in Fort Portal municipality. Other prior studies undertaken in Uganda indicate poor or lack of sanitary inspection in majority of the public eating places [18].

Sorting of wastes was not done at majority of the stalls assessed. This was not done because highway vendors were not aware of good waste management practices since most of them indicated lack of sanitation training among their challenges. Failure to sort wastes can result in multiplication of pathogenic organisms in the wastes which may be transferred to the food by flies or hand contact resulting in contamination of food [19].

Majority of the stalls assessed did not have waste collection facilities (not even sacks or boxes to put wastes). The high percentage of stalls with no waste collection facilities was largely due to inadequate sensitisation among vendors about the need to effectively manage wastes during food preparation. This can be attributed partly to weakness of the leadership of the market and other local health authorities in the areas where these markets are located. Vending stalls should be designed and constructed so that they have areas designated for collecting wastes [1].

\section{Conformity to recommended conditions of water supply at the stall}

Most stalls $(>50 \%)$ did not have adequate quantities of water. Unavailability and inadequacy of water at the stalls is explained by the high costs of acquiring water. A 20 litre jerrican of tap water was sold at 300-500 Uganda shillings (Approximately 0.2USD) as compared to National Water and Sewerage Cooperation charges 20 litres at 23 Uganda shillings (approximately 0.007USD). This is not good at all for the safety of the food that is prepared and sold in food vending markets since water that is used repeatedly without replacement could facilitate bacterial growth thus resulting in contamination of food [21]. Inadequacy of water at the stalls in Najembe and Lukaya markets is also explained by the long distances to the water sources and inadequate sources of water around the two highway markets studied. Inadequacy of water at the stalls was also due to lack of awareness on the importance of washing food handling utensils [21].

The observed indicators of water quality (colour, physical impurities and smell) indicated the quality of water was poor denoting low conformity. The low conformity 


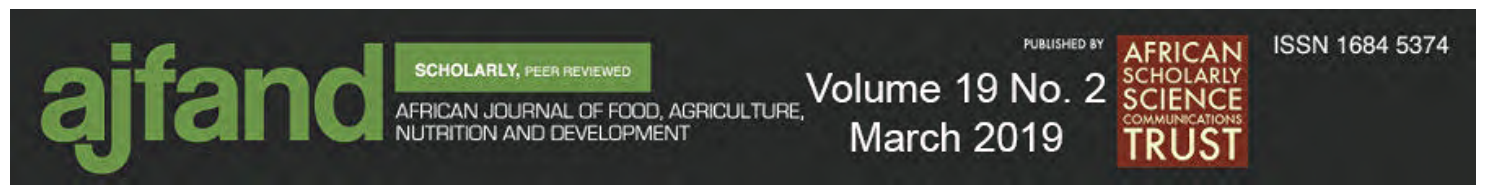

at the stalls of vendors was largely due to poor storage facilities and practices for water. Water was stored in dirty containers. The recommended best practices require that water storage containers should be of food grade and must be used solely for the purpose of storing and serving water and should not have been used previously for any other purposes which could cause contamination of the water that is stored in them [7].

\section{Conformity of shared facilities (toilet/latrine, solid waste and waste water management facilities) to recommended conditions}

The conformity of shared facilities (toilet/latrine, solid waste and waste water management facilities) was generally low. This was exhibited by a small number of latrine stances that served many vendors. On average the latrines served at least 80-88 users per stance in the markets. This is contrary to the WHO standards of 25 users per stance. Generally, the section for the ladies appeared cleaner as compared to men's. Most latrines had dilapidated roof tops, no water for washing hands, the floors were wet and had flies on the walls. This provides a suitable environment for easy contamination of food stuffs through direct contact with the excreta [21]. There were no visible drainage channels in the markets and wastewater was stagnant in all corners of the markets as vendors poured it on the ground next to their stalls. Wastes should not be allowed to accumulate in food handling, food storage and other working areas of food and the adjoining environment [8]. Spaces that are close to waste disposal sites should be kept appropriately clean [3].

\section{CONCLUSION}

The sanitation facilities for all the stalls across the two markets studied were not fully conforming to recommendation sanitation standards. Most stalls for chicken, beef and goat meat had low levels of conformity. Also, majority of the vendors were not implementing proper sanitation practices. The low conformity of sanitation facilities across all the stalls is attributed to poor market infrastructure such as latrines/toilets, vending structures, drainage systems and solid waste collection facilities that are in poor state of repair. The poor sanitation practices are due to lack of awareness among the meat vendors and inadequate monitoring by the local health authorities. The absence of drainage facilities, adequate cleaning equipment and the bad state of repair of vending structures in both markets has negative implications to the safety of the vended meat products. To address the above gaps in sanitation, vendors should ensure that solid waste material is handled in such a manner as to avoid contamination of food and potable water. All work surfaces, utensils, table- tops, floors and surrounding areas should be thoroughly and routinely cleaned, at least daily. The market chairpersons and their committee members should ensure there is sufficient supply of potable water. They should also ensure that the markets have an efficient waste water disposal system which should be properly maintained. In addition, the vendors should be periodically trained in good sanitation practices. 


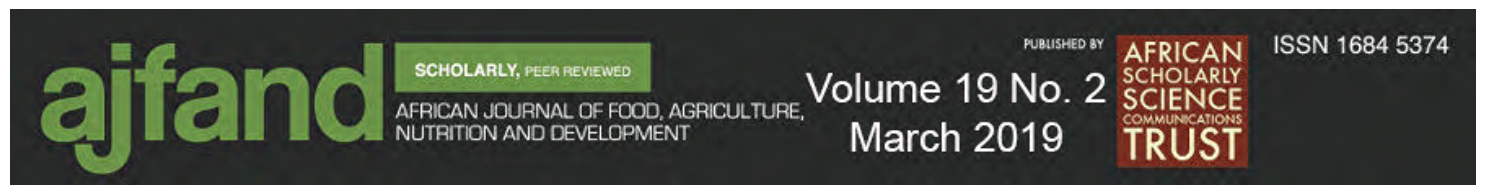

Table 1: Conformity to recommended conditions of waste management facilities

\begin{tabular}{|c|c|c|c|c|c|}
\hline Observations & Scores & $\begin{array}{l}\text { Number of } \\
\text { recommended } \\
\text { conditions }\end{array}$ & $\begin{array}{c}\text { Najembe } \\
(\mathbf{\%}) \\
\mathbf{N}=\mathbf{2 0}\end{array}$ & $\begin{array}{c}\text { Lukaya } \\
(\%) \\
\mathbf{N}=\mathbf{2 1}\end{array}$ & $\begin{array}{l}\text { Average \% } \\
\text { for Najembe } \\
\text { and Lukaya }\end{array}$ \\
\hline $\begin{array}{l}\text { Existence of wastes at the } \\
\text { stall }\end{array}$ & & 3 & & & \\
\hline High level conformity & 4 & & - & - & - \\
\hline Good conformity & 3 & & 14 & 5 & 10 \\
\hline Fair conformity & 2 & & - & - & - \\
\hline Low conformity & 1 & & 38 & 70 & 54 \\
\hline Non-conformity & 0 & & 48 & 25 & 37 \\
\hline Sorting of wastes & & 3 & & & \\
\hline High level conformity & 4 & & - & - & - \\
\hline Good conformity & 3 & & 1 & 1 & 1 \\
\hline Fair conformity & 2 & & 1 & 4 & 3 \\
\hline Low conformity & 1 & & 4 & 3 & 4 \\
\hline Non-conformity & 0 & & 94 & 92 & 93 \\
\hline $\begin{array}{l}\text { Existence of waste collection } \\
\text { facilities }\end{array}$ & & 1 & & & \\
\hline High level conformity & 4 & & 24 & 20 & 22 \\
\hline Good conformity & 3 & & - & - & - \\
\hline Fair conformity & 2 & & - & - & - \\
\hline Low conformity & 1 & & - & - & - \\
\hline Non-conformity & 0 & & 76 & 80 & 78 \\
\hline $\begin{array}{l}\text { Effectiveness of waste } \\
\text { collection facilities }\end{array}$ & & 6 & & & \\
\hline High level conformity & 4 & & - & - & - \\
\hline Good conformity & 3 & & 5 & - & 3 \\
\hline Fair conformity & 2 & & - & 3 & 2 \\
\hline Low conformity & 1 & & 19 & 17 & 18 \\
\hline Non-conformity & 0 & & 76 & 80 & 78 \\
\hline
\end{tabular}

(4=High level conformity, 3= Good conformity, 2=Fair conformity, 1=Low

conformity, 0 = non-conformity) 


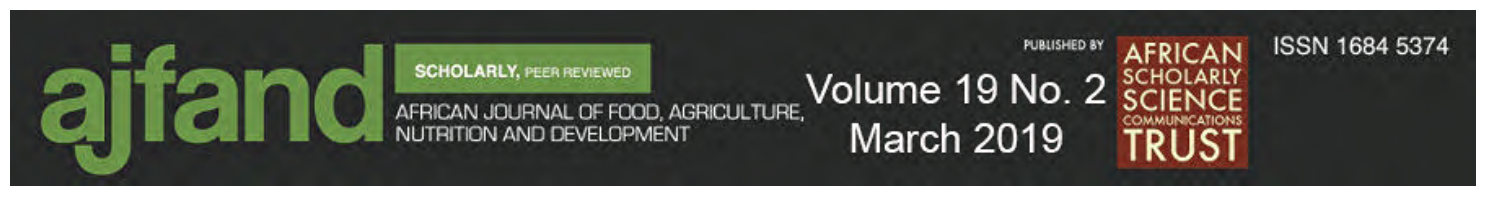

Table 2: Conformity to recommended conditions of water at the stall

\begin{tabular}{|c|c|c|c|c|c|}
\hline Observations & Scores & $\begin{array}{c}\text { Number of } \\
\text { recommended } \\
\text { conditions }\end{array}$ & $\begin{array}{c}\text { Najembe } \\
(\%) \\
\mathbf{N}=\mathbf{2 0} \\
\end{array}$ & $\begin{array}{c}\text { Lukaya } \\
(\%) \\
\mathbf{N}=21 \\
\end{array}$ & $\begin{array}{c}\text { Average \% for } \\
\text { Najembe and } \\
\text { Lukaya }\end{array}$ \\
\hline $\begin{array}{l}\text { Availability of water at } \\
\text { the stall }\end{array}$ & & 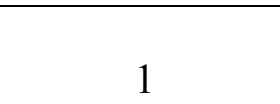 & & & \\
\hline High level conformity & 4 & & 57 & 65 & 61 \\
\hline Good conformity & 3 & & - & - & - \\
\hline Fair conformity & 2 & & - & - & - \\
\hline Low conformity & 1 & & - & - & - \\
\hline Non-conformity & 0 & & 43 & 35 & 39 \\
\hline $\begin{array}{l}\text { Adequacy of the water } \\
\text { observed at the stall }\end{array}$ & & 1 & & & \\
\hline High level conformity & 4 & & 26 & 37 & 32 \\
\hline Good conformity & 3 & & - & - & - \\
\hline Fair conformity & 2 & & - & - & - \\
\hline Low conformity & 1 & & - & - & - \\
\hline Non-conformity & 0 & & 74 & 63 & 68 \\
\hline Observed water quality & & 4 & & & \\
\hline High level conformity & 4 & & 3 & 7 & 5 \\
\hline Good conformity & 3 & & 15 & 29 & 22 \\
\hline Fair conformity & 2 & & 42 & 35 & 38 \\
\hline Low conformity & 1 & & 27 & 18 & 23 \\
\hline Non-conformity & 0 & 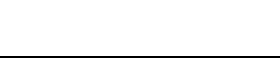 & 13 & 11 & 12 \\
\hline
\end{tabular}




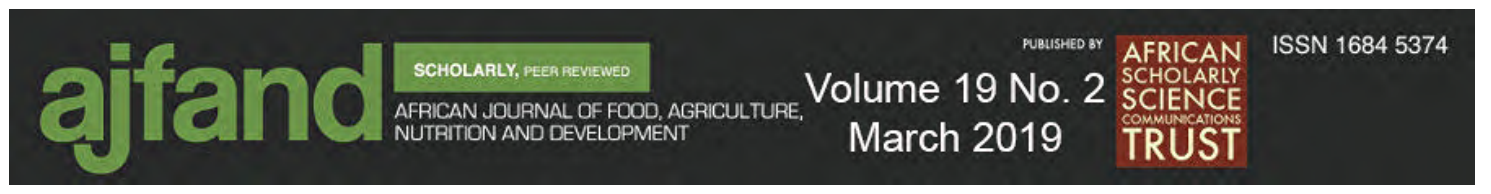

Table 3: Conformity to recommended conditions for toilet/latrine, solid waste and waste water management facilities

\begin{tabular}{lccc}
\hline Facility & $\begin{array}{c}\text { Number of recommended } \\
\text { conditions }\end{array}$ & \multicolumn{2}{c}{ Scores } \\
& 11 & 1 & Najembe \\
\hline Latrines/toilets & 4 & 3 & 1 \\
$\begin{array}{l}\text { Solid waste disposal } \\
\text { facilities }\end{array}$ & 2 & 0 & 0 \\
$\begin{array}{l}\text { Waste water management } \\
\text { facilities }\end{array}$ & & & \\
\hline
\end{tabular}

Details of the assessment of excreta, solid waste and waste water management facilities

\begin{tabular}{llcc}
\hline Facility & Recommended conditions & Najembe & Lukaya \\
Latrines/toilets & Latrine/Toilet adequacy & 0 & 1 \\
& Distance of the latrine/toilet from the stalls & 1 & 0 \\
& Condition of the walls & 1 & 1 \\
& Floor dryness and cleanliness & 0 & 0 \\
& Conditions of the roof & 0 & 1 \\
& Presence of tissue paper & 0 & 0 \\
& Presence of a hand washing area & 0 & 1 \\
& Absence of flies & 1 & 0 \\
& Door & 1 & 1 \\
& Presence of latrine cover & 0 & 0 \\
Solid waste & Label indicating where latrine/toilet is & 0 & 1 \\
disposal & Distance of rubbish pit from stalls & 1 & 0 \\
facilities & Fullness of rubbish pit & 1 & 0 \\
& Leachates at the rubbish pit & 1 & 1 \\
Waste water & Absence of flies & 0 & 0 \\
disposal & Absence of waste water in the market & 0 & 0 \\
facilities & Presence of drainage channels & 0 & 0 \\
(4=High level conformity, 3= Good conformity, 2=Fair conformity, 1=Low conformity, \\
$0=$ non-conformity)
\end{tabular}




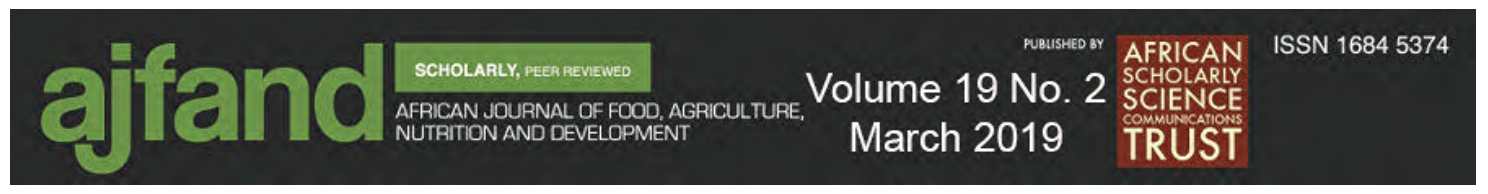

Table 4: Results from the assessment of sanitation practices

\begin{tabular}{|c|c|c|c|}
\hline Area covered & Najembe & Lukaya & $\begin{array}{c}\text { Average percentage for Najembe } \\
\text { and Lukaya }(\%)\end{array}$ \\
\hline \multicolumn{4}{|l|}{ Sanitation challenges } \\
\hline $\begin{array}{l}\text { Inadequate cleaning and } \\
\text { sanitization materials }\end{array}$ & 68 & 77 & 73 \\
\hline $\begin{array}{l}\text { Insufficient knowledge } \\
\text { about good sanitation } \\
\text { practices }\end{array}$ & 69 & 65 & 67 \\
\hline $\begin{array}{l}\text { Inadequate clean } \\
\text { latrine/toilet facilities }\end{array}$ & 74 & 78 & 76 \\
\hline $\begin{array}{l}\text { Inadequate solid and liquid } \\
\text { waste disposal facilities }\end{array}$ & 58 & 80 & 69 \\
\hline $\begin{array}{l}\text { Inadequate sources of } \\
\text { clean water }\end{array}$ & 83 & 59 & 71 \\
\hline \multicolumn{4}{|l|}{ Sorting of wastes } \\
\hline Sort wastes & 6 & 12 & 9 \\
\hline Do not Sort wastes & 94 & 88 & 91 \\
\hline \multicolumn{4}{|c|}{ Adequacy of waste handling equipment } \\
\hline Adequate & 10 & 24 & 17 \\
\hline Inadequate & 90 & 76 & 83 \\
\hline
\end{tabular}




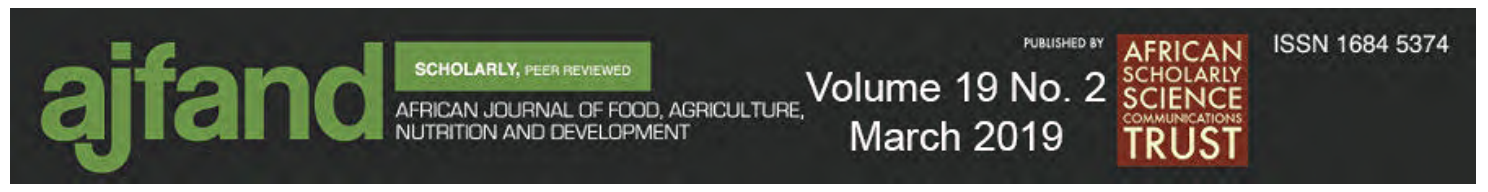

\section{REFERENCES}

1. Sebudde $\mathbf{S}$, Kabagambe $\mathbf{R}$ and $\mathbf{M}$ Muganwa Hygiene and sanitation in public eating places in one municipal health system of Uganda. Kampala: Erudite $J$. Med. and Med. Sc. Res. (EJMMSR).2012; 1(1): 1-8.

2. Mensah P Street Food in Accra, Ghana: how safe are they? Bulletin of the World Health Organization. 2012; 80: 546-556.

3. Winnie VM Street vending in African cities: A synthesis of empirical findings from Kenya, Cote D'Ivoire, Ghana, Zimbabwe, Uganda and South Africa. Background Paper for the 2005 World Development Report, Institute for Development Studies University of Nairobi. 2005; 9: 4-30.

4. Mbaguta A Sanitation for the Urban Poor in Uganda. UWASNET, Kampala, Uganda

5. MoH Annual Health Sector Review Report, Republic of Uganda. 2012.

6. Muyanja C, Nayiga L, Namugumya B and G Nasinyama Practices, knowledge and risk factors of street food vendors in Uganda. Food control. 2011; 22(10): 1551 .

7. Muinde $\mathbf{O}$ Hygienic and sanitary practices of vendors of street foods in Nairobi, Kenya. Afric. J. Food Agric. Nutri. and Dev'nt. 2005; 7: 1684-5378.

8. Barry M Handling money and serving ready-to-eat foods. J. Food. ser. Tech. 2005;2: 1-3.

9. Odu N Microbiological Quality of Street-Vended-Ready-To-Eat "Bole" Fish In Port Harcourt Metropolis. N.Y. Sci. J. 2013; 6 (in press).

10. USFDA Draft Methodological Approach to Identifying High-Risk Foods under Section 204(d)(2) of the FSMA. 2013

http://www.fda.gov/Food/GuidanceRegulation/FSMA/ucm380210.htm.

(Accessed 10 $0^{\text {th }}$ January 2016).

11. FAO. General requirements (food hygiene). Codex Alimentrarious, FAO, Rome. $1995 ; 188-192$.

12. Bagumire A and R Karumuna Hygiene Facilities and Practices for Vended Meats at Selected Highway Markets in Uganda. J. Food and Nutri. Sc.2017; 5(1): $1-10$.

13. Bagumire A and $\mathbf{R}$ Karumuna Bacterial contamination of ready-to-eat meats vended in highway markets in Uganda, Afric. J. Food. Sc. 2017; Vol. 11(6): 160170.

14. The Food and Drugs Act of 1964, Cap 278 of Laws of Uganda.

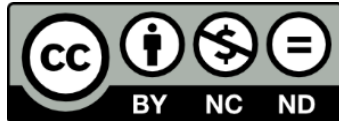




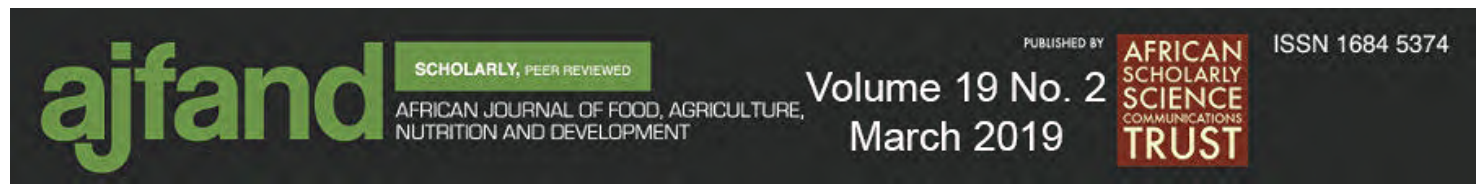

15. Republic of Uganda. The Public Health Act of 1969. Uganda Legal Information Institute.

16. MAAIF. The manual of standard operating procedures for fish inspection and quality assurance, $2^{\text {nd }}$ Ed Department of Fisheries Resources, Entebbe Uganda. 2011.

17. Bagumire A, Todd ECD, Nasinyama GW and C Muyanja Food Safety-related measures in the emerging aquaculture enterprises in Sub-Saharan Africa: Compliance of Uganda's operations against international market requirements. Afric. J. Food. Sc. 2010; 4(7): 444-457.

18. Nabiwemba LE Excreta Disposal and Accessibility to Water in Kyebando, A peri-urban Area in Kampala. Unpublished MSc. dissertation, Makerere University, Uganda; 1997.

19. Chirag G Study of Hygienic practices of street food vendors in Allahabad city, India and Determination of Critical control points for safe street food, The Allahabad Farmer; 2013; 68: 2.

20. FAO/WHO. Regional guidelines for the design of control measures for streetvended foods (Africa). Codex Alimentarius Supplement, FAO/WHO Codex Alimentarius Commission, Joint FAO/WHO food standards program. Agriculture and consumer protection department, FAO, Rome; 1997.

21. Abdalla MA, Suliman SE and AO Bakhiet Food safety knowledge and practices of street-food vendors in Atbara City (NaherElneel State Sudan). Afric. J. Biotech. 2009; 8(24): 6967-6971. 